\title{
Release of Potassium in Association with Structural Evolution During Biomass Combustion
}

\author{
Wenhan $\mathrm{Cao}^{1}$, Jun $\mathrm{Li}^{1 *}$, Leteng $\mathrm{Lin}^{2}$, Xiaolei Zhang ${ }^{1}$ \\ ${ }^{1}$ Department of Chemical and Process Engineering, University of Strathclyde, Glasgow G1 1XJ, UK \\ ${ }^{2}$ Department of Built Environment and Energy Technology, Linnaeus University, Växjö 351 95, Sweden
}

\begin{abstract}
A mechanistic understanding of potassium release is essential to mitigate the potassiuminduced ash problems during biomass combustion. This work studies the effects of operational condition on the potassium release and transition during the combustion of wheat straw, and elucidate the release potential of potassium associated to the structural change of biomass particles. The combustion tests were carried out in a laboratory-scale reactor, working in a wide range of temperatures and heating rates. It was found that the combustion of biomass sample at a temperature up to $1000^{\circ} \mathrm{C}$ results in a release of over $60 \%$ of its initial potassium content. Raising the heating rate from $8^{\circ} \mathrm{C} / \mathrm{min}$ to $25^{\circ} \mathrm{C} / \mathrm{min}$ could lead to an additional release of up to $20 \%$ of the initial amount of potassium. A three-stage potassium release mechanism has been concluded from this work: the initial-step release stage (below $400^{\circ} \mathrm{C}$ ), the holding stage $(400-$ $700^{\circ} \mathrm{C}$ ) and the second-step release stage (above $700^{\circ} \mathrm{C}$ ). Comprehensive morphology analysis with elemental (i.e. $\mathrm{K}, \mathrm{S}, \mathrm{O}, \mathrm{Si}$ ) distribution was carried out; the results further confirmed that potassium is likely to exist inside the stem-like tunnel of biomass particles, mainly in forms of inorganic salts. During the heating-up process, the breakdown and collapse of biomass particle structure could expose the internally located potassium and thus accelerate the release of potassium and the transform of its existing forms. Lastly, a detailed temperature-dependent release mechanism of potassium was proposed, which could be used as the guidance to mitigate the release of detrimental potassium compounds by optimising the combustion process.
\end{abstract}

\footnotetext{
* Corresponding Author: Dr Jun Li (email: jun.li@strath.ac.uk; Phone: +44 (0)141 548 2393)
} 
Keywords: Biomass; Combustion; Potassium; Release mechanism

\section{Introduction}

Energy depletion, environmental pollution and climate change due to the increasing utilization of fossil fuels have motivated a global imperative to explore alternative energy sources [1]. Biomass is a $\mathrm{CO}_{2}$-neutral renewable energy source with great potential to replace fossil fuels as it is the only renewable energy resource that contains all elements needed for the generation of fuels and related products [2]. Around 10-15\% of world energy demand is currently supplied from biomass, which is equivalent to about 1.25 billion tons of oil $[3,4]$. Lignocellulosic biomass can be converted to energy via thermochemical conversions, such as pyrolysis, gasification, and combustion. Of which combustion is the only proven technology today to utilize biomass sources for heat and power production at large scales [5-7]. However, ashrelated problems such as slagging, fouling and corrosion remain as major technical challenges in biomass combustion, which are mainly caused by the release of alkali species (especially K) along with other corrosive inorganic elements (e.g. S and $\mathrm{Cl}$ ) [8].

The $\mathrm{K}$ content in woody and herbaceous biomass is typically around $0.4 \%$ and $1.3 \%$ by weight, respectively [9]. It is reported that $60-90 \%$ of $\mathrm{K}$ in these biomass materials can be released as vapours during combustion at temperatures above $1000^{\circ} \mathrm{C}$ [10-12]. Those volatile potassium vapours will undergo homogeneous reactions forming compounds. As the flue gas cools down, these compounds form new primary particles by nucleation or condense on surfaces of existing fly ash particles. Primary particles can grow further by condensation, coagulation and agglomeration during the travel with the flue gas, and finally, form the fine mode particle emission to our ambient. Furthermore, a part of the sticky submicron ash particles could also condense on the hot surfaces of walls and pipes in boilers to form layers of sticky deposit and capture the subsequent particles. Studies have been carried out on the K release mechanisms 
and concluded that $\mathrm{KCl}, \mathrm{KOH}$ and $\mathrm{K}_{2} \mathrm{SO}_{4}$ are the dominate forms of generated potassium vapours during combustion. A general release mechanism can be summarised as: (1) Organically-associated and loosely-bonded $\mathrm{K}$ will release at temperatures up to $500^{\circ} \mathrm{C}$; (2) As the temperature further increases, char-bonded and inorganic $\mathrm{K}$ species start releasing till a large portion; (3) $\mathrm{K}-(\mathrm{Al})-\mathrm{Si}-\mathrm{Ti}$ compounds, known as insoluble $\mathrm{K}$ species, remain in solid residues after the completion of char oxidation at high temperatures [1].

During biomass combustion, the release of K can be affected by fuel composition and operating conditions such as temperature and heating rate. Fuel composition normally affects the yields and forms of $\mathrm{K}$ species released during biomass combustion [13]. The existence of $\mathrm{Cl}$ could act as a main facilitator of the $\mathrm{K}$ release, whereas $\mathrm{Si} / \mathrm{Al}$ contents in the virgin biomass are favourable to the $\mathrm{K}$ retention. Si-rich biomass sample is capable of capturing the $\mathrm{K}$ content and preventing its release as $\mathrm{KCl}[10]$. Several studies have revealed that most herbaceous and woody biomass can release $70-90 \%$ of their initial $\mathrm{K}$ content as combustion temperature reaches $1150^{\circ} \mathrm{C}$ [11]. The operating conditions (i.e. temperature and heating rate) can significantly affect the reaction kinetics of biomass devolatilisation, thereby the yield of the evaporated volatile matter and potentially the release of $\mathrm{K}$.

Biomass normally contains a higher amount of volatile matter, most of which can be released at relatively low temperatures. A release of such large amount of volatile matter can intensify the release of associated $\mathrm{K}$ and affect the distribution of existing $\mathrm{K}$ forms in the char products. The heating process during the combustion could affect the volatile release and manipulate the structural changes of biomass particles, which closely correlate with the intraparticle heat and mass transfer, the ash formation and the pollutant formations [14]. It is thus of great interests to elucidate the effects of thermal processing conditions on the $\mathrm{K}$ transition associated with structural changes during biomass combustion. Currently available publications, however, focused mainly on the release behaviour of $\mathrm{K}$ from burning biomass samples in a preheated 
reactor at temperatures around $1000^{\circ} \mathrm{C}[9,15-22]$. Little is known on the effects of operational conditions on the structural change of biomass particles and the transition of $\mathrm{K}$.

This study will investigate the effects of the final temperature and heating rate on the release and transition of $\mathrm{K}$ during biomass combustion. Analyses will be carried out based on the structural changes of biomass particles and the distributions of key inorganic elements. Insights of the knowledge are anticipated for the development of ash-problem-free biomass combustion technologies prolonging the service life of biomass boilers, and making the energy from biomass more competitive [23].

\section{Materials and Methods}

2.1 Raw materials and test device

Wheat straw pellets were used as raw material in this study, purchased from Agripellets Ltd. The average weight of each straw pellet is ca. $0.8 \mathrm{~g}$ in a cylinder shape with a length of $40 \mathrm{~mm}$ and a diameter of $5 \mathrm{~mm}$. The straw pellets have been air-dried to eliminate the excess amount of moisture. Table 1 listed the fuel properties of wheat straw pellets. It shows that the sample contains higher amounts of $\mathrm{K}$ and $\mathrm{S}$. The $\mathrm{Cl}$ content, however, is rather low, indicating that the potassium release via the $\mathrm{KCl}$ pathway is negligible.

Table 1. Fuel properties of wheat straw material

\begin{tabular}{|c|c|c|c|c|c|}
\hline \multirow[t]{4}{*}{ Proximate analysis, wt $\%$} & Moisture $^{a r}$ & 9.00 & ${ }^{\#}$ Ash analysis, wt $\%$ & $\mathrm{SiO}_{2}$ & 31.88 \\
\hline & $\mathrm{VM}^{d b}$ & 74.80 & & $\mathrm{Al}_{2} \mathrm{O}_{3}$ & 0.86 \\
\hline & $* A s h{ }^{d b}$ & 7.40 & & $\mathrm{CaO}$ & 5.24 \\
\hline & $\mathrm{FC}^{d b}$ & 17.80 & & $\mathrm{MgO}$ & 1.61 \\
\hline \multirow[t]{6}{*}{ Ultimate analysis, wt $\%$} & $\mathrm{C}^{d b}$ & 45.20 & & $\mathrm{Na}_{2} \mathrm{O}$ & 0.12 \\
\hline & $\mathbf{H}^{d b}$ & 5.25 & & $\mathrm{~K}_{2} \mathrm{O}$ & 9.13 \\
\hline & $\mathrm{O}^{d b}$ & 48.69 & & $\mathrm{P}_{2} \mathrm{O}_{5}$ & 46.74 \\
\hline & $\mathbf{N}^{d b}$ & 0.71 & & $\mathrm{Fe}_{2} \mathrm{O}_{3}$ & 0.15 \\
\hline & $\mathrm{Cl}^{d b}$ & 0.01 & & $\mathrm{TiO}_{2}$ & $<0.05$ \\
\hline & $\mathbf{S}^{d b}$ & 0.14 & & Other & 2.5 \\
\hline
\end{tabular}

Note: ar $=$ as received basis; db $=$ dry basis.

* ash content determination temperature: $800^{\circ} \mathrm{C}$; ${ }^{\#}$ ashing temperature: $550^{\circ} \mathrm{C}$. 
Combustion experiments were carried out in a laboratory-scale high-temperature furnace equipped with a weighing system. A schematic drawing of the furnace is shown in Figure 1. The system allows the monitoring of the weight loss of the biomass samples during experiments, a time-dependent temperature profile of the biomass sample is monitored using the thermocouple located in the middle of the furnace. The prepared samples are heated inside the furnace from ambient to the target temperature at a given heating rate, then holding for 10 min. The mild heating processes and long holding time can allow the heat sufficiently transferred from the environment, to the crucible container and eventually to biomass sample with a minimized temperature gradient and make sure the reactions are completed. After reactions, samples will be transferred and cool down in a drying oven that is maintained at ambient temperature. The validation and the reliability tests of the furnace have been carried out by comparing its mass loss and derivative mass loss results with that of the TGA device. According to the tests, the furnace can accurately identify the different stages during the biomass combustion and the obtained volatile matter and ash contents are varied within 5\% compared to that of the TGA results $[23,24]$. There are totalling of 18 combustion tests were performed, the operating conditions of these tests are summarised in Table 2. For each test, $5 \mathrm{~g}$ wheat straw pellets were weighted with an error of $\pm 0.1 \mathrm{~g}$, and each pellet is in cylinder shape and selected with a length of $40( \pm 1) \mathrm{mm}$ and diameter of $5( \pm 0.1) \mathrm{mm}$. The effect of final combustion temperatures was investigated in the ranged of $300^{\circ} \mathrm{C}$ to $1000^{\circ} \mathrm{C}$ (with $100^{\circ} \mathrm{C}$ interval) while the heating rate was kept constant at $17^{\circ} \mathrm{C} / \mathrm{min}$. The effect of different heating rates was tested for $8^{\circ} \mathrm{C} / \mathrm{min}, 17^{\circ} \mathrm{C} / \mathrm{min}$ and $25^{\circ} \mathrm{C} / \mathrm{min}$; and for each heating rate, five final temperatures $\left(300^{\circ} \mathrm{C}, 400^{\circ} \mathrm{C}, 600^{\circ} \mathrm{C}, 900^{\circ} \mathrm{C}\right.$ and $\left.1000^{\circ} \mathrm{C}\right)$ were applied, representing the typical temperatures of sequential conversion stages during the biomass combustion. Each combustion test was carried out twice to ensure the repeatability of the results, and the averaged quantity result is shown in this study. 
Table 2. Summary of performed combustion tests of biomass samples

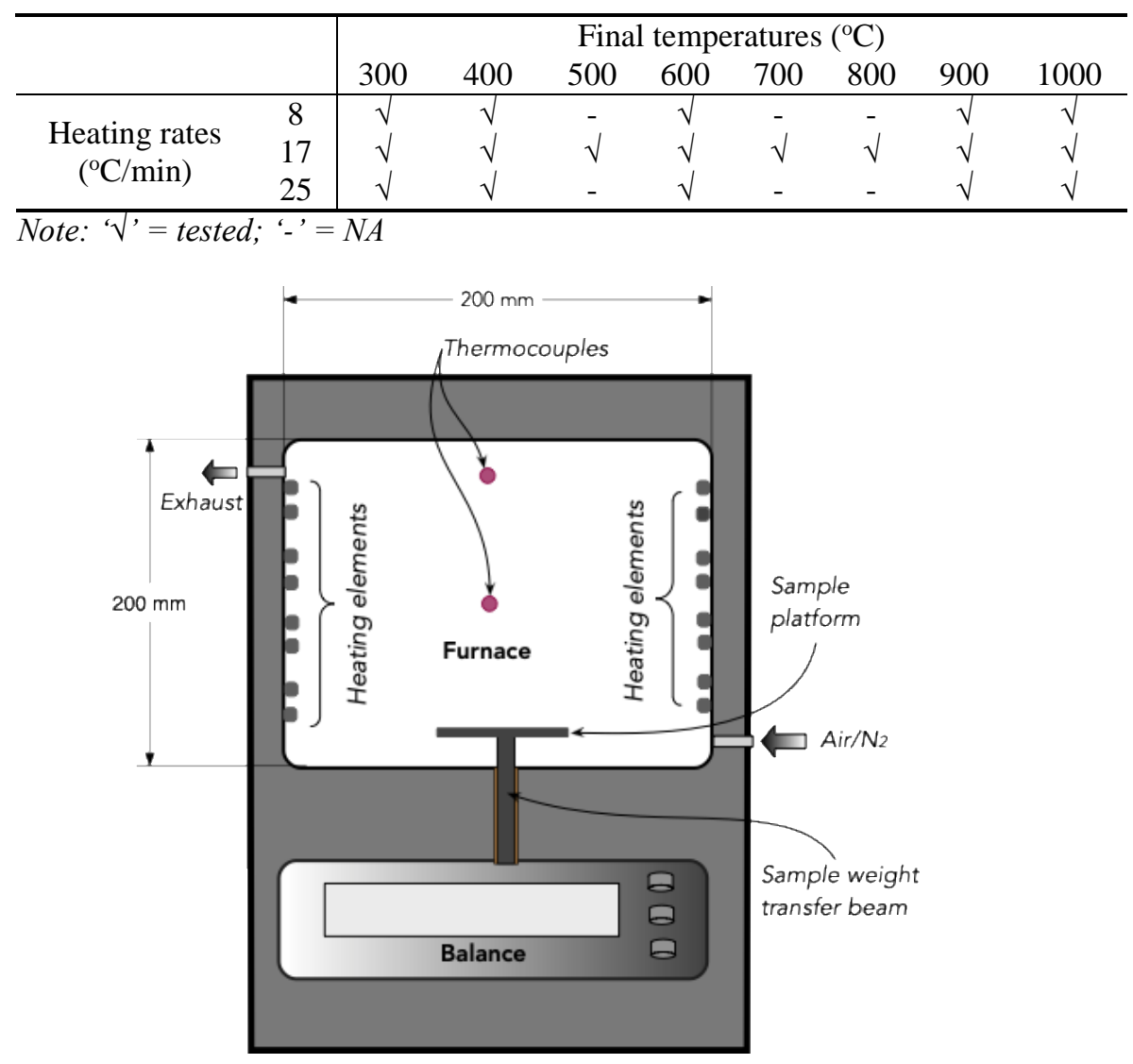

Figure1. Schematic drawing of the furnace equipped with weighing system

\subsection{Determination of $\mathrm{K}$ content in solid residues}

After each combustion test, the remaining residues were collected and milled into fine particles. Then $50( \pm 5) \mathrm{mg}$ residue sample was digested in the $\mathrm{HNO}_{3}$ solution (> 69\%) using a microwave oven at $200^{\circ} \mathrm{C}$ for 120 minutes. Samples of the digested solutions were then analysed for K content using Inductively Coupled Plasma Optical Emission Spectroscopy (ICP-OES). Collected solid samples were further analysed by Scanning Electron Microscopy - Energy Dispersive X-ray Spectroscopy (SEM-EDX) in order to elucidate the change of structure of the particles and scope the distributions of the target inorganic elements. These results will be jointly analysed to determine the transition performance of $\mathrm{K}$ species. The quantity and morphology analysis were all repeated twice to ensure the reproductivities of the 
results. The standard deviations of all the measurements are within the range of $0.1-0.5 \%$ (see Table A and Table B in the supplementary materials), indicates a small variation of the results.

Since biomass sample undergoes drying, devolatilisation and char oxidation during its combustion process, the $\mathrm{K}$ content in the solid residues would be concentrated and might vary according to the conversion stage. For comparison purposes, $\mathrm{K}$ content will be normalized for the amount of $\mathrm{K}$ in the fuel and presented with a unit of $\mathrm{mg} / \mathrm{kg}$ raw biomass material. The released $\mathrm{K}$ concentration $R_{k} *$ can be calculated as below:

$$
R_{k}^{*}=1-\frac{m_{k} C_{r}}{m_{o}} 100 \%
$$

Where $\mathrm{m}_{\mathrm{k}}$ represents the $\mathrm{K}$ content in the remaining solid residue, $\pm 0.001 \mathrm{mg} / \mathrm{kg}, \mathrm{C}_{\mathrm{r}}$ is the ratio of the mass of the remaining residue to the initial mass, $\pm 0.1 \%$, and $\mathrm{m}_{0}$ is the initial $\mathrm{K}$ content in the raw wheat straw, $\pm 0.001 \mathrm{mg} / \mathrm{kg}$.

\section{Results and Discussion}

\subsection{Effects of the final temperature on $\mathrm{K}$ transition}

Most of the free potassium in living biomass is presented in the form of ions $\left(\mathrm{K}^{+}\right)$in solution within the xylem cells [25]. During the air-drying process, these ions precipitate as inorganic $\mathrm{K}$ salts [26], which make up to $90 \%$ of the total $\mathrm{K}$ in raw biomass thermally stable at lower temperatures. The release of $\mathrm{K}$ and the mass loss of wheat straw samples as a function of temperatures is presented in Figure 2. The transition of K species could be categorised as three stages: the initial-step release $\left(<400^{\circ} \mathrm{C}\right)$, the K-holding phase $\left(400^{\circ} \mathrm{C}-700^{\circ} \mathrm{C}\right)$, and the secondstep release $\left(>700^{\circ} \mathrm{C}\right)$. The potential transition mechanism of $\mathrm{K}$ at each stage will be analysed and discussed later individually. In order to facilitate the further understanding of $\mathrm{K}$ transition fate, a list of potential chemical reactions is presented in Table 3 regarding the transformation of relevant potassium species during biomass combustion. 


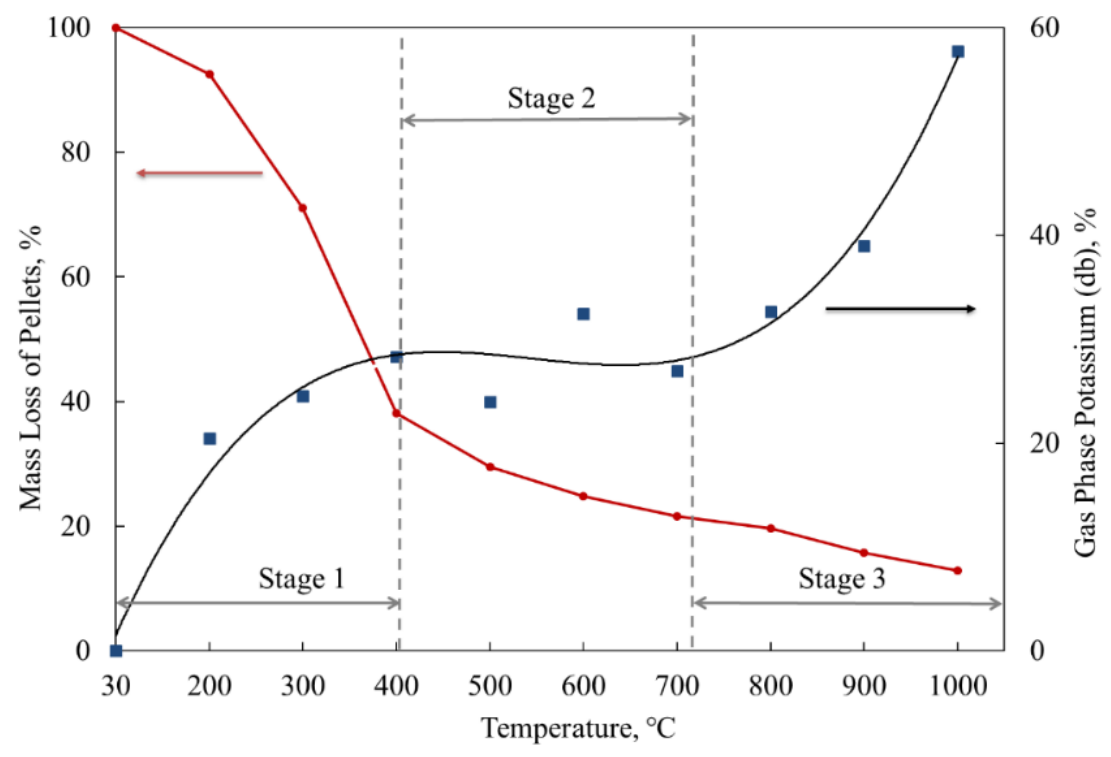

Figure 2. Mass loss and the released gas phase $\mathrm{K}$ on dry basis at the heating rate of $17^{\circ} \mathrm{C} / \mathrm{min}$

Table 3. Potential reactions of $\mathrm{K}$ species during the combustion process

\begin{tabular}{llc}
\hline & & Ref. \\
\hline $\mathrm{R}-\mathrm{COOK}(\mathrm{s}) \rightarrow \mathrm{R}+\mathrm{CO}_{2}(\mathrm{~g})+\mathrm{K}(\mathrm{g})$ & $\mathrm{R} 1$ & {$[1]$} \\
$2 \mathrm{~K}(\mathrm{~g})+2 \mathrm{H}_{2} \mathrm{O}(\mathrm{g}) \rightarrow 2 \mathrm{KOH}(\mathrm{g})+\mathrm{H}_{2}(\mathrm{~g})$ & $\mathrm{R} 2$ & {$[27]$} \\
$2 \mathrm{KOH}(\mathrm{g})+\mathrm{CO}_{2}(\mathrm{~g}) \rightarrow \mathrm{K}_{2} \mathrm{CO}_{3}(\mathrm{~s})+\mathrm{H}_{2} \mathrm{O}(\mathrm{g})$ & $\mathrm{R} 3$ & {$[28]$} \\
$\mathrm{Char}-\mathrm{K}(\mathrm{s})+\mathrm{O}_{2}(\mathrm{~g}) \rightarrow \mathrm{K}_{2} \mathrm{CO}_{3}(\mathrm{~s})$ & $\mathrm{R} 4$ & {$[12]$} \\
$\mathrm{Char}-\mathrm{K}(\mathrm{s})+\mathrm{S} \rightarrow \mathrm{K}_{2} \mathrm{SO}_{4}(\mathrm{~s})$ & $\mathrm{R} 5$ & {$[21]$} \\
$\mathrm{K}_{2} \mathrm{CO}_{3}(\mathrm{~s})+\mathrm{H}_{2} \mathrm{O}(\mathrm{g}) \rightarrow 2 \mathrm{KOH}_{(\mathrm{g})+\mathrm{CO}_{2}(\mathrm{~g})}$ & $\mathrm{R} 6$ & {$[17]$} \\
$\mathrm{K}_{2} \mathrm{CO}_{3}(\mathrm{~s}) \rightarrow \mathrm{K}_{2} \mathrm{O}(\mathrm{s})+\mathrm{CO}_{2}(\mathrm{~g})$ & $\mathrm{R} 7$ & {$[17]$} \\
$2 \mathrm{~K}_{2} \mathrm{O}(\mathrm{s}, 1) \rightarrow 4 \mathrm{~K}(\mathrm{~g})+\mathrm{O}_{2}(\mathrm{~g})$ & $\mathrm{R} 8$ & {$[11]$} \\
$\mathrm{K} / \mathrm{K}_{2} \mathrm{O}(\mathrm{s})+\mathrm{SiO}_{2}(\mathrm{~s}) \rightarrow \mathrm{K}_{2} \mathrm{SiO}_{3}(\mathrm{~s})$ & $\mathrm{R} 9$ & {$[29]$} \\
\hline
\end{tabular}

\subsubsection{Stage 1: The initial-step release (up to $400^{\circ} \mathrm{C}$ )}

The initial-step release of $\mathrm{K}$ occurs at temperatures below $400^{\circ} \mathrm{C}$. As shown in Figure 2, around $30 \%$ of $\mathrm{K}$ in the initial biomass released at $200^{\circ} \mathrm{C}$, where straw pellet starts decomposition too. At temperatures below $300^{\circ} \mathrm{C}$, loosely-bonded $\mathrm{K}$ in the biomass that is attached to hydroxyl and/or carboxyl groups, or other oxygen-containing groups [30, 31] can be released from the surfaces of particles in the form of $\mathrm{K}^{+}(\mathrm{g})[32,33]$. Those $\mathrm{K}^{+}(\mathrm{g})$ can subsequently react with water vapour locally available to form $\mathrm{KOH}(\mathrm{g})$ that is the primary $\mathrm{K}$ form released at temperatures below $400^{\circ} \mathrm{C}[30,34]$. When the temperature increases up to $400^{\circ} \mathrm{C}$, there is 
around $15 \%$ of $\mathrm{K}$ in the initial biomass being further released (see Figure 2). During this stage, a steep weight loss of straw pellets occurred with approximately $70 \%$, mainly due to the enhanced devolatilisation. When the final temperature reaches $400^{\circ} \mathrm{C}$, partial organic-K starts decomposing (via R1) while inorganic-K remains stable as this temperature is not high enough to initiate the evaporation and decomposition of inorganic-K compounds. The wheat straw pellets used in the tests are Cl-lean according to the ultimate analysis in Table 1, implying $\mathrm{KOH}$ is the main form of the released $\mathrm{K}$ (which is partially generated via $\mathrm{R} 2$ ). At $400^{\circ} \mathrm{C}$, a significant amount of volatile matter has released from straw biomass, and the volatile hydrocarbons would be partially oxidised into $\mathrm{CO}_{2}$ [35]. The released $\mathrm{KOH}$ vapour could go through carbonation reaction ( $\mathrm{R} 3$ shown in Table 3 ) to form new particles and/or condense on the surface of existing particles in the form as $\mathrm{K}_{2} \mathrm{CO}_{3}$ via nucleation and condensation routines at this temperature.

Table 4 presents the SEM and EDX images of the morphology and distributions of key relevant elements $(\mathrm{K}, \mathrm{O}, \mathrm{S}$ and $\mathrm{Si})$ on the surfaces of the solid samples collected after each combustion test. Looking at the sample particles prepared below $400^{\circ} \mathrm{C}$, their structure has not been changed much as indicated by SEM images for $200^{\circ} \mathrm{C}$ and $400^{\circ} \mathrm{C}$ samples. Their EDX images show that the surface area of the examined particles is covered with $\mathrm{O}$ in the majority, and $\mathrm{Si}$ and $\mathrm{K}$ only at the detectable level. However, $\mathrm{K}$ and $\mathrm{S}$ are revealed more abundant in the internal structures than on the surfaces of the particles as observed through the cross-section areas of the char particle combusted at $400{ }^{\circ} \mathrm{C}$ (denoted as $400{ }^{\circ} \mathrm{C}$-char). Only a small amount of $\mathrm{S}$ is detected, indicating that $\mathrm{K}_{2} \mathrm{SO}_{4}$ may not be the main existing form of $\mathrm{K}$ in the wheat straw. 
Table 4. Results of morphology and surface elemental composition of biomass solid residues characterized by

SEM-EDX

\begin{tabular}{|c|c|c|c|c|c|c|}
\hline & \multicolumn{6}{|c|}{ Final temperature $\left({ }^{\circ} \mathrm{C}\right)$} \\
\hline & 200 & 400 & 600 & 700 & 900 & 1000 \\
\hline $\begin{array}{c}\text { Mass } \\
\text { conversion } \\
\text { of biomass } \\
\text { (wt.\%) }\end{array}$ & 7.5 & 61.8 & 75.2 & 78.4 & 84.3 & 87.2 \\
\hline SEM & & & & & & \\
\hline $\begin{array}{c}\text { EDX } \\
\text { (Red: K; } \\
\text { Green: O; } \\
\text { Blue: S) }\end{array}$ & & & & & & \\
\hline $\begin{array}{c}\text { EDX } \\
\text { (Red: K; } \\
\text { Green: O; } \\
\text { Blue: Si) }\end{array}$ & & & & & & \\
\hline
\end{tabular}

During the devolatilisation stage, weakly bonded moieties in biomass particles will disconnect

from the main structure via bond breakage, forming vapour molecules that accumulate within the particle [36]. Volatiles, together with loosely-bonded K, will burst forth from the particle due to the internal force built up by gas pressure. Meanwhile, new stronger and cross-linked bonds can be formed by reconnecting broken structures with neighbouring active regions. During the internal structure change of the carbonaceous material, i.e. the char-forming process, the organic- $K$ is starting to convert into char- $K$ via internal molecular rearrangements. At the same time, the original biomass particle will become more porous due to the release of volatiles. In our results, most of the stem-like structure remains intact up to $400{ }^{\circ} \mathrm{C}$ as shown in the $400^{\circ} \mathrm{C}$-char SEM image in Table 4. Some breakage and percolative fragmentation [37] will 
take place depending on the original structure of biomass, the heating rate applied and the final temperature attained by particles. At the final temperature of $400{ }^{\circ} \mathrm{C}$, the breakage of particles is visible where more internally located $\mathrm{K}$ is exposed. However, the release of those $\mathrm{K}$ is insignificant in the current situation, implying that the major $\mathrm{K}$ exists in the internal structure of biomass is thermally stable. At this temperature, the retention of $\mathrm{K}$ via the reaction with the Si-rich layers to form stable K silicates is rather negligible [11]. This suggests that the exposed mode of internally located $\mathrm{K}$ could be inorganic salts such as $\mathrm{K}_{2} \mathrm{SO}_{4}$ and $\mathrm{K}_{2} \mathrm{CO}_{3}$, together with some stable char-K derived from organic-K [1].

\subsubsection{Stage 2: The K-holding phase $\left(400-700^{\circ} \mathrm{C}\right)$}

The K-holding phase, i.e. almost no noticeable increase of the K release (see Figure 2), occurs in the temperature range of $400-700^{\circ} \mathrm{C}$ where decomposition and partial char oxidation occurs after the devolatilisation [38]. The release of $\mathrm{K}$ is insignificant, whereas the transition of the $\mathrm{K}$ compounds from organic to inorganic forms is very likely to take place at this holding stage. When the final temperature reaches $700^{\circ} \mathrm{C}$, there is only about $20 \mathrm{wt} \%$ of the original sample remained as the solid residue, mainly consisting of ash and unburnt char.

Compared with the SEM image of $400^{\circ} \mathrm{C}$-char, the structure of $600^{\circ} \mathrm{C}$-char particles do not show a significant change as shown in Table 4. Similar to the $400^{\circ} \mathrm{C}$-char, the particle of $600^{\circ} \mathrm{C}$-char is not fully collapsed yet, and the stem-like structure is recognizable with explicit channels. The original biomass used in this study has a high content of Si (as indicated in Table 1) which should present with silicate skeletons offering necessary structural strength against the possible collapse [11]. However, the structure of channels in the $600^{\circ} \mathrm{C}$-char looks less dense, and surfaces of the char particle become rougher with the attachment of fine ash particles visible. The EDX image of $600^{\circ} \mathrm{C}$-char reveals more $\mathrm{K}$ and $\mathrm{S}$ on the broken side surface than that in the image of $400^{\circ} \mathrm{C}$-char. Those substantial amount of $\mathrm{K}$ and $\mathrm{S}$ inside the pores are possibly $\mathrm{K}_{2} \mathrm{SO}_{4}$ (s) that are formed via the $\mathrm{R} 5$ (see Table 3) in the presence of oxygen. Besides, 
the observed K-Si clusters in Table 4 suggest the co-existence of $\mathrm{K}$ and $\mathrm{Si}$ (apart from the inherent $\mathrm{K}_{2} \mathrm{SiO}_{3}$ in biomass). They, however, may not form any compound yet, because the reaction between the two elements cannot be significant at $600^{\circ} \mathrm{C}$ [1]. This implies that the $\mathrm{K}$ is likely to be captured by the Si matrix at the current stage of the char combustion. The possibility of incorporating alkali metal oxides into silicate networks has been proved by previous works $[33,39,40]$. If the temperature keeps rising up, the captured $\mathrm{K}$ could further react with Si to form different type of silicates.

As a short summary for this $\mathrm{K}$-holding stage, char-K and organic-K are partially trapped by silicate structure and/or partially go through transition routes. Char-K is partially oxidized to produce $\mathrm{K}_{2} \mathrm{CO}_{3}$ in the solid phase via the reaction of $\mathrm{R} 4$ during the char combustion with the presence of excess oxygen and partially react with $\mathrm{S}$ forming $\mathrm{K}_{2} \mathrm{SO}_{4}(\mathrm{~s})$. At the end of this stage, the remaining $\mathrm{K}$ in the char/ash residues exists mainly in the form of thermally-stable carbonate and sulphate.

\subsubsection{Stage 3: The second-step release (above $700^{\circ} \mathrm{C}$ )}

The second-step release of $\mathrm{K}$ occurs when the final temperature exceeds $700^{\circ} \mathrm{C}$. The high temperature facilitates further combustion of the remaining char, which is indicated by a further $10 \%$ of weight loss of solid samples in Figure 2. Meanwhile, the dissociation and release of alkali salts are also enhanced, which is evident with a significant $\mathrm{K}$ release of an additional $30 \%$ of its initial mass. After the organic- $\mathrm{K}$ and partial inorganic- $\mathrm{K}$ released at low-medium temperatures, the remaining $\mathrm{K}$ exists mainly in the forms of $\mathrm{K}_{2} \mathrm{CO}_{3}, \mathrm{~K}_{2} \mathrm{SO}_{4}$ and $\mathrm{K}_{2} \mathrm{SiO}_{3}$. When the final temperature exceeds $800^{\circ} \mathrm{C}$, the formed $\mathrm{K}_{2} \mathrm{CO}_{3}(\mathrm{~s})$ could be either vaporised or react with $\mathrm{H}_{2} \mathrm{O}$ to generate $\mathrm{KOH}$ (g) via the R6 (see Table 3). If the temperature goes above $900^{\circ} \mathrm{C}$, $\mathrm{K}_{2} \mathrm{CO}_{3}$ (s) could be primarily dissociated to $\mathrm{K}_{2} \mathrm{O}$ (s) and $\mathrm{K}(\mathrm{g})$, following the $\mathrm{R} 7$ and $\mathrm{R} 8$ [11]. Previous studies also reported that the formation of K-Si species following the R9 becomes 
significant at the combustion temperature above $900^{\circ} \mathrm{C}[11,41] . \mathrm{K}_{2} \mathrm{SO}_{4}(\mathrm{~s})$ could be evaporated from $1000^{\circ} \mathrm{C}$ and above [12], resulting in a further loss of $\mathrm{K}$ content from solid residues. After complete combustion of biomass samples at high temperatures, the remaining $\mathrm{K}$ in the ash residues is presented mainly in the thermally stable forms, such as $\mathrm{K}_{2} \mathrm{SiO}_{3}(\mathrm{~s}), \mathrm{K}_{2} \mathrm{O}$ (s), and/or possible forms like $\mathrm{K}_{2} \mathrm{CaSiO}_{4}(\mathrm{~s})$ and $\mathrm{KAlSi}_{3} \mathrm{O}_{8}(\mathrm{~s})$ [29].

According to Table 4, the structure and surface of $900^{\circ} \mathrm{C}$-char and $1000^{\circ} \mathrm{C}$-char have changed significantly during this stage compared with the samples made for other stages. The char particle shrank as the pore structure collapsed. Moreover, fine ash particles adhere to the surface of larger residue particles. The edges of the particles become less sharp, especially shown by the $1000^{\circ} \mathrm{C}$-char. The EDX images of both $900^{\circ} \mathrm{C}$-char and $1000^{\circ} \mathrm{C}$-char show that more internally located $\mathrm{K}$ and $\mathrm{S}$ is detected from the surface on the broken section of pore structure. While carbon is consumed and released during combustion, the collapse and breakage of the particle pore structure occur. A peeling role is played to get more internally located $\mathrm{K}$ and Si-rich structure exposed first, and then react with each other. For the $900^{\circ} \mathrm{C}$ char, partial fusion is found on the external surfaces of the larger particles where $\mathrm{Si}$ and $\mathrm{K}$ are relatively rich. For the $1000^{\circ} \mathrm{C}$-char, the pore structure is not visible any more. Large external area is fused, and particles start to agglomerate into the large structure with smooth surfaces. The evaporation of $\mathrm{K}_{2} \mathrm{SO}_{4}$ (s) can still take place at this temperature. Therefore, the $\mathrm{K}$ and $\mathrm{S}$ clusters become less abundant. However, $\mathrm{K}$ and Si clusters became more detectable, together with the isolated $\mathrm{K}$ and $\mathrm{K}-\mathrm{O}$ clusters. This suggests that the Si matrix could effectively capture the $\mathrm{K}(\mathrm{s})$ and $\mathrm{K}_{2} \mathrm{O}(\mathrm{s})$ after being released. As a further fate reported in the studies [33, 42], $\mathrm{K}_{2} \mathrm{SiO}_{3}$ (s) can be partially released as well, causing the further loss of $\mathrm{K}$ if the final temperature exceeds $1200^{\circ} \mathrm{C}$. Meanwhile, the trapped $\mathrm{K}$ (s) and $\mathrm{K}_{2} \mathrm{O}$ (s) could further react with $\mathrm{Ca}$ to form $\mathrm{K}-\mathrm{Ca}$-silicate that can remain stable in the molten ash residues.

\subsubsection{Proposal of a comprehensive temperature-dependent K-transition pathway}


By summarizing the above resulting data, we proposed a comprehensive K-transition mechanism during the combustion process as presented in Figure 3, which fully illustrates the transition behaviour of $\mathrm{K}$ at different temperatures. This mechanism involves solid-phase- $\mathrm{K}$ transition pathways that are contributed from this work (black-coloured in Figure 3) and the gas-phase-K transition routes integrated from the literature $[1,10,12,21]$ (blue-coloured in Figure 3). When the combustion process is running below $800^{\circ} \mathrm{C}$, the release of loosely bounded $\mathrm{K}$ and organic- $\mathrm{K}$ are mainly in the form of $\mathrm{KOH}$. It is worth to mention that in this study $\mathrm{KCl}$ plays an insignificant role due to the low content of $\mathrm{Cl}$ in wheat straw. In addition to its release, $\mathrm{K}$ in the fuel could simultaneously undergo different transformation routes, such as (1) the capture of released $\mathrm{K}$ compounds by Si-matrix due to the continuous change of particle structures and further exposure of internally located $\mathrm{K}$; (2) the transformation from organic-K to char-K within the solid residue; (3) the oxidization and sulphation of char-K to form the thermally-stable salts like $\mathrm{K}_{2} \mathrm{CO}_{3}$ and $\mathrm{K}_{2} \mathrm{SO}_{4}$. During the progress of its oxidation, the particle structure will gradually change from a rigid and porous network to a shrunk and collapsed skeleton. This could indirectly affect the $\mathrm{K}$ transition pathway. When the final temperature exceeds $800^{\circ} \mathrm{C}$, the abundant decomposition and evaporation of inorganic $\mathrm{K}$ compounds (like $\mathrm{K}_{2} \mathrm{CO}_{3}$ and $\mathrm{K}_{2} \mathrm{SO}_{4}$ ) will dominate the released volatile $\mathrm{K}$ species. Meanwhile, the retention of $\mathrm{K}$ will occur through reactions between $\mathrm{Si}$ and the captured $\mathrm{K}$ to form thermally-stable $\mathrm{K}$ silicates [11, 41]. 


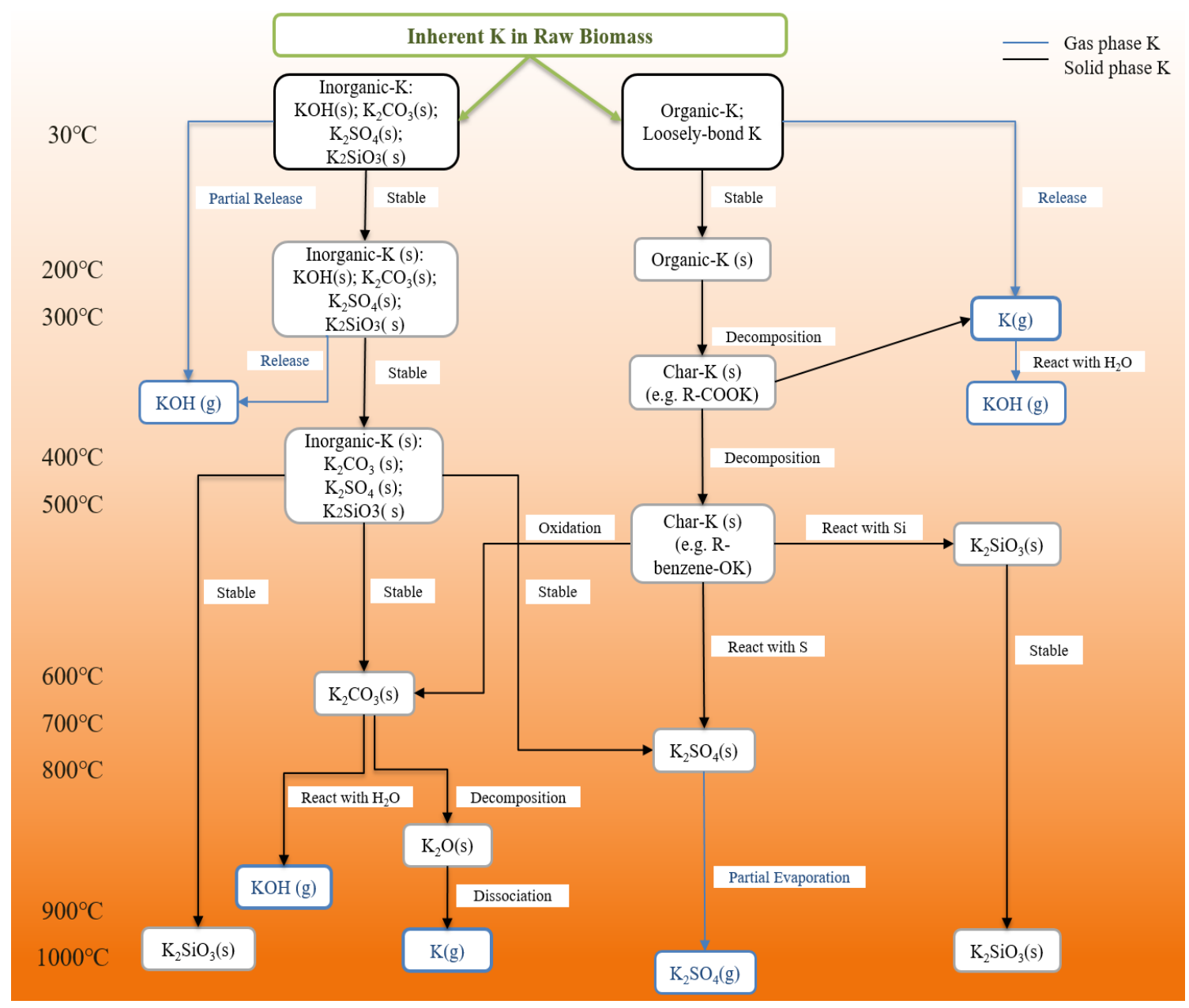

Figure 3. Temperature-dependent transition route of $\mathrm{K}$ during combustion integrated with the reported pathways (adapted from literature $[1,10,12,21]$ )

\subsection{Effects of the heating rate on $\mathrm{K}$ transition}

The effects of heating rate on the release of $\mathrm{K}$ are summarised in Figure 4. The three stages of K transition defined in Section 3.1 are well distributed but varying slightly under different heating rates. A similar trend is observed for each group of tests at the same final temperatures. That is, the higher the heating rate is applied, the more $\mathrm{K}$ is released. However, the released amounts of $\mathrm{K}$ at the heating rate of $8^{\circ} \mathrm{C} / \mathrm{min}$ and $17^{\circ} \mathrm{C} / \mathrm{min}$ are rather similar, with differences of approximately $5 \%$. Compared with the cases of the heating rate of $8^{\circ} \mathrm{C} / \mathrm{min}$, the cases with the heating rate of $25{ }^{\circ} \mathrm{C} / \mathrm{min}$ release about $15-20 \%$ more $\mathrm{K}$ in the initial-release stage, around $15 \%$ more in the K-holding stage, and about $10-15 \%$ more in the second-release stage. 


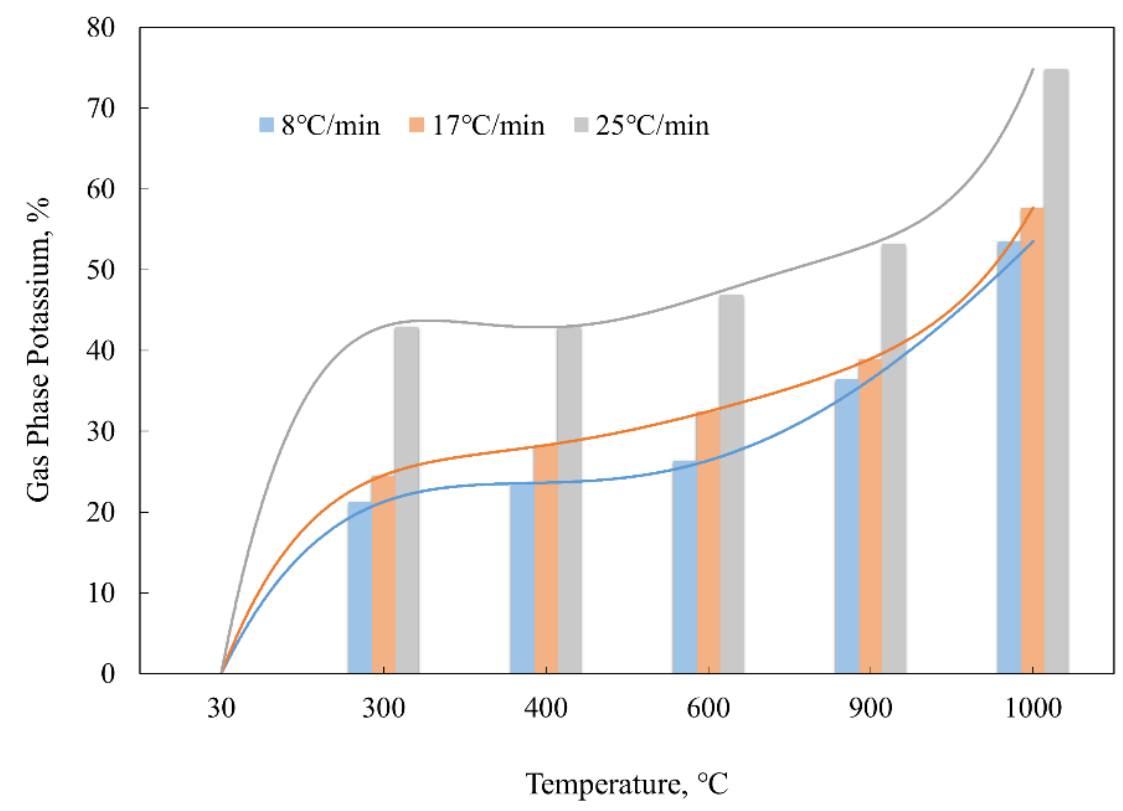

Figure 4. The change of $\mathrm{K}$ content (dry basis) released in gas phase with the change of heating rate

According to the literature [43-45], the high heating rate can enhance the probability of simultaneous bond breaking, leading to a higher release of volatile matters within a shorter time during the devolatilisation stage. The conversion rates of the tested samples under the different heating rates are summarised in Figure 5. It illustrates a higher heating rate results in a higher conversion rate of the samples during combustion, similar results were also reported by Fushimi et al. [46]. As aforementioned in Section 3.1, the release of K starts with the release of loosely bonded $\mathrm{K}$ and organic- $\mathrm{K}$ that could be associated with the evaporation of volatile matters. Nevertheless, the conversion differences are not very big among our tested biomass samples which are heated to the same final temperature with varied heating rates. The reason is twofold: firstly, all these studied three applied heating rates are basically slow which may not bring noticeable conversion difference; and secondly, the effect of the total heating time, especially the final isothermal holding time, might equalize or compromise the difference among conversions caused by the small variations of low heating rates applied. 


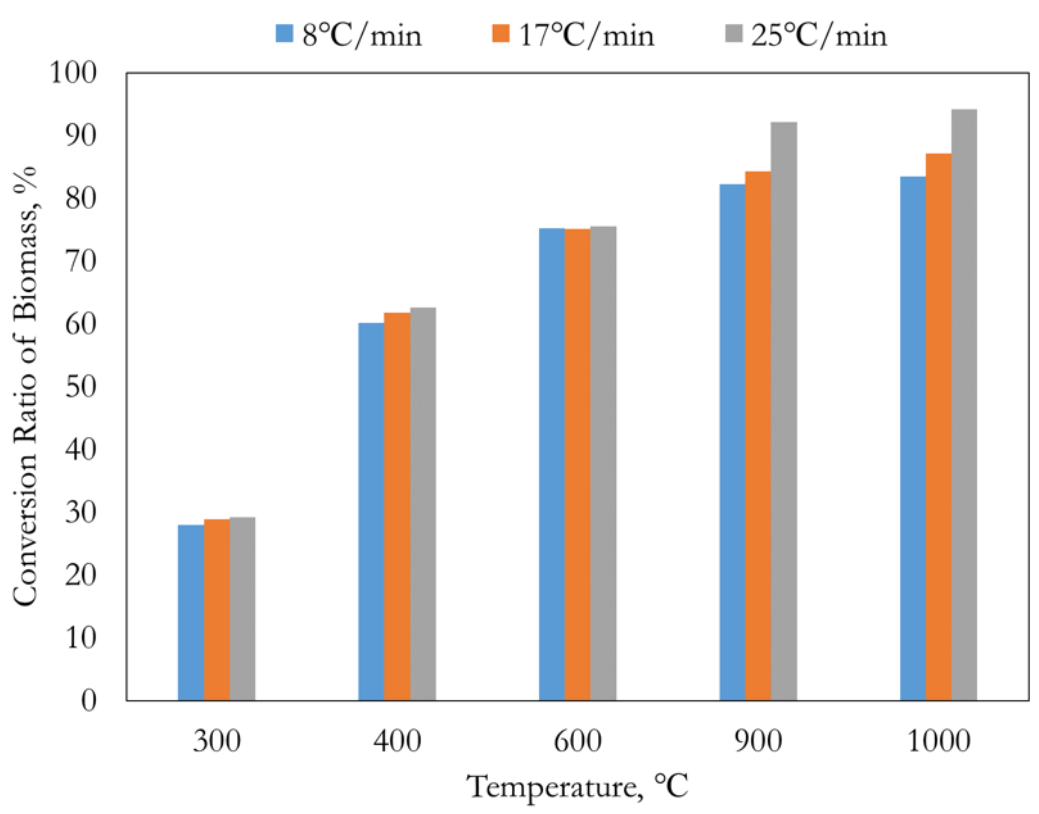

Figure 5. Mass conversions of biomass at different heating rates

Furthermore, the effect of heating rate on the K release and transition could also be explained theoretically based on the apparent activation energy of biomass decomposition and potassium bond dissociation energies (BDEs). The energy supplied to the biomass particles could determine as to whether the dissociations of the potassium bonds occur. A higher heating rate provides a rapid energy supply that accelerates the molecular motions, benefiting the biomass decomposition reactions [47]. Besides, it was reported that a higher heating rate might lower the apparent activation energy of biomass decomposition reactions [48-50], the apparent activation energy for typical biomass decomposition reactions are approximately $180 \mathrm{~kJ} / \mathrm{mol}$ [51]. When compared with the theoretical BDEs to break the $\mathrm{K}$ bonds as listed in Table 5, it is noticed that the BDEs of $\mathrm{K}^{+}$-X bonds and organic-K are all within $100 \mathrm{~kJ} / \mathrm{mol}$, well below the apparent activation energy of $180 \mathrm{~kJ} / \mathrm{mol}$. This indicates that the dissociation of $\mathrm{K}^{+}-\mathrm{X}$ bonds and organic-K are prioritised during the decomposition process. Besides, a higher heating rate leads to an extensive devolatilisation [52], resulting in $\mathrm{H}_{2} \mathrm{O}$ and $\mathrm{HCl}$ released at higher concentrations. Additionally, a higher heating rate can suppress surface diffusion [53]. Therefore, the dissociated $\mathrm{K}^{+} / \mathrm{K}$ from the organic- $\mathrm{K}$ and $\mathrm{K}^{+}-\mathrm{X}$ are able to departure the particle 
more quickly. These free gaseous $\mathrm{K}^{+}$would then be more likely to react with gaseous species of $\mathrm{H}_{2} \mathrm{O}$ and $\mathrm{HCl}$ to generate the corresponding $\mathrm{K}$ compounds, i.e. $\mathrm{KOH}$ and $\mathrm{KCl}$.

Table 5. Theoretical bond dissociation energy (BDE) of typical K bonds

\begin{tabular}{llll}
\hline The $\mathrm{K}$ bonds & BDE, kJ/mol & The $\mathrm{K}$ bonds & BDE, kJ/mol \\
\hline $\mathrm{K}-\mathrm{H}$ & 183.4 & $\mathrm{~K}^{+}-\mathrm{O}$ & 17.5 \\
$\mathrm{~K}-\mathrm{Cl}$ & 433.0 & $\mathrm{~K}^{+} \mathrm{KCl}$ & 172 \\
$\mathrm{~K}-\mathrm{O}$ & 276.1 & $\mathrm{~K}^{+} \mathrm{CO}$ & 19 \\
$\mathrm{~K}-\mathrm{OH}$ & 359.0 & $\mathrm{~K}^{+}-\mathrm{CO}_{2}$ & 35.6 \\
$(\mathrm{KO})-\mathrm{H}$ & 521.7 & $\mathrm{~K}^{+}-\mathrm{KOH}$ & 159.0 \\
$(\mathrm{KOH})-\mathrm{KOH}$ & 190.0 & $\mathrm{~K}^{+}-(\mathrm{KOH})_{2}$ & 126.0 \\
$\mathrm{~K}-\mathrm{H}_{2} \mathrm{O}$ & 24.1 & $\mathrm{~K}^{+}-\mathrm{H}_{2} \mathrm{O}$ & 70.7 \\
$\mathrm{~K}-\mathrm{NH}_{3}$ & 31.2 & $\mathrm{~K}^{+}-\mathrm{K}_{2} \mathrm{SO}_{4}$ & 159.0 \\
$\mathrm{~K}-\mathrm{K}$ & 57.0 & $\mathrm{~K}^{+}\left(\mathrm{CH}_{3} \mathrm{OH}\right)-\mathrm{H}_{2} \mathrm{O}$ & 65.2 \\
$\mathrm{~K}^{+}-\mathrm{K}$ & 85.7 & $\mathrm{~K}^{+}-\mathrm{C}_{2} \mathrm{H}_{5} \mathrm{C}(\mathrm{O}) \mathrm{OH}$ & 87 \\
$\mathrm{~K}^{+}-\mathrm{Cl}$ & 26.9 & $\mathrm{~K}^{+}-\mathrm{C}_{6} \mathrm{H}_{5} \mathrm{OH}$ & 83.7 \\
$\mathrm{~K}^{+}-\mathrm{CH}_{3} \mathrm{OCH}_{3}$ & 92.9 & & \\
\hline
\end{tabular}

*BDEs are extracted from the reference [54]

Table 6 presents SEM-EDX images of morphology and surface elemental distribution mapping of biomass solid residues, which are prepared at varying heating rates and different final temperatures. We index the presented images in Table 6 using a common name format as B-8400 , indicating the solid residue derived with a heating rate of $8{ }^{\circ} \mathrm{C} / \mathrm{min}$ at the final temperature of $400^{\circ} \mathrm{C}$. It is found that the influence of the heating rate on the change of particle structure at the low and medium temperatures $\left(400^{\circ} \mathrm{C}\right.$ and $\left.600^{\circ} \mathrm{C}\right)$ is insignificant, and the porous structure of particles are well reserved without evident breakage and pore collapse. The effect of the heating rate on the morphology is not apparent for all samples collected from tests at $400^{\circ} \mathrm{C}$ and $600^{\circ} \mathrm{C}$. At high temperatures $\left(900^{\circ} \mathrm{C}\right.$ and $\left.1000^{\circ} \mathrm{C}\right)$, however, the particles undertake dramatic structural changes compared to that at lower temperatures. Large cavities and openness, as well as the fused structure, appear more obviously and frequently in the high heating rate samples than in the low heating rate samples. This can be observed by comparing the morphology between B-8-900 and B-25-900. The pore collapse, coalescence and fusing behaviours are well illustrated in the SEM image of B-25-900. Samples combusted at $1000^{\circ} \mathrm{C}$ 
also show similar fused morphology, with denser structures and smoother surfaces, due to the high ash content in the solid residues with a high conversion rate.

Elemental distribution mapping results from EDX show several general trends: (1) K is widely spread within the whole particle structure for all samples made at lower temperatures of $400^{\circ} \mathrm{C}$ and $600^{\circ} \mathrm{C}$. However, it is less distributed on the surfaces and more concentrated inside the pore structure for all samples collected from tests at $900^{\circ} \mathrm{C}$ and $1000^{\circ} \mathrm{C}$. (2) Si-clusters reveal several more locally concentrated patterns for all B-8 samples (representing all samples prepared with a lower heating rate of $8^{\circ} \mathrm{C} / \mathrm{min}$ at all tested temperatures) in comparison to more evenly-distributed within the structures for all B-25 samples. The pore structure opening during the devolatilisation stage and further surface reaction of combustion will lead to more internally located $\mathrm{K}$ exposed. As shown in Table 6, K distribution on the surface of the B-25-400 sample is more abundant than that of both B-8-400 and B-17-400 samples.

The high heating rate could increase the char reactivity [55] by lowering the pyrolytic carbon deposition, inhabiting secondary carbonisation reaction [56] and generating more active sites [57]. This would accelerate the decomposition and conversion of char-K and thus form more inorganic $\mathrm{K}$ compounds (i.e. $\mathrm{KOH}, \mathrm{K}_{2} \mathrm{CO}_{3}$ and $\mathrm{K}_{2} \mathrm{SO}_{4}$ ). They can either be dissociated and evaporated or be retained as silicates at high temperatures [23]. For example, the B-25-1000 sample shows much less $\mathrm{K}$ distributed on its surface than the B-8-1000 sample, due to the potentially enhanced release of $\mathrm{K}_{2} \mathrm{SO}_{4}$. While the surface distribution of $\mathrm{K}-\mathrm{S}$ clusters shows less abundant in the B-17-900 and B-25-900 samples than that in the B-8-900 sample. Moreover, little S distribution is detected on either the side or fragmented surface for all B1000 samples. Futhermore, less K but more Si start distributing on the surfaces for all samples of B-900 and B-1000 indicating the final $\mathrm{K}$ retention via the formation of $\mathrm{K}_{2} \mathrm{SiO}_{3}$. 
Table 6. SEM-EDX Results of morphology and surface elemental distribution of sample residues collected from tests at different final temperatures and heating rates

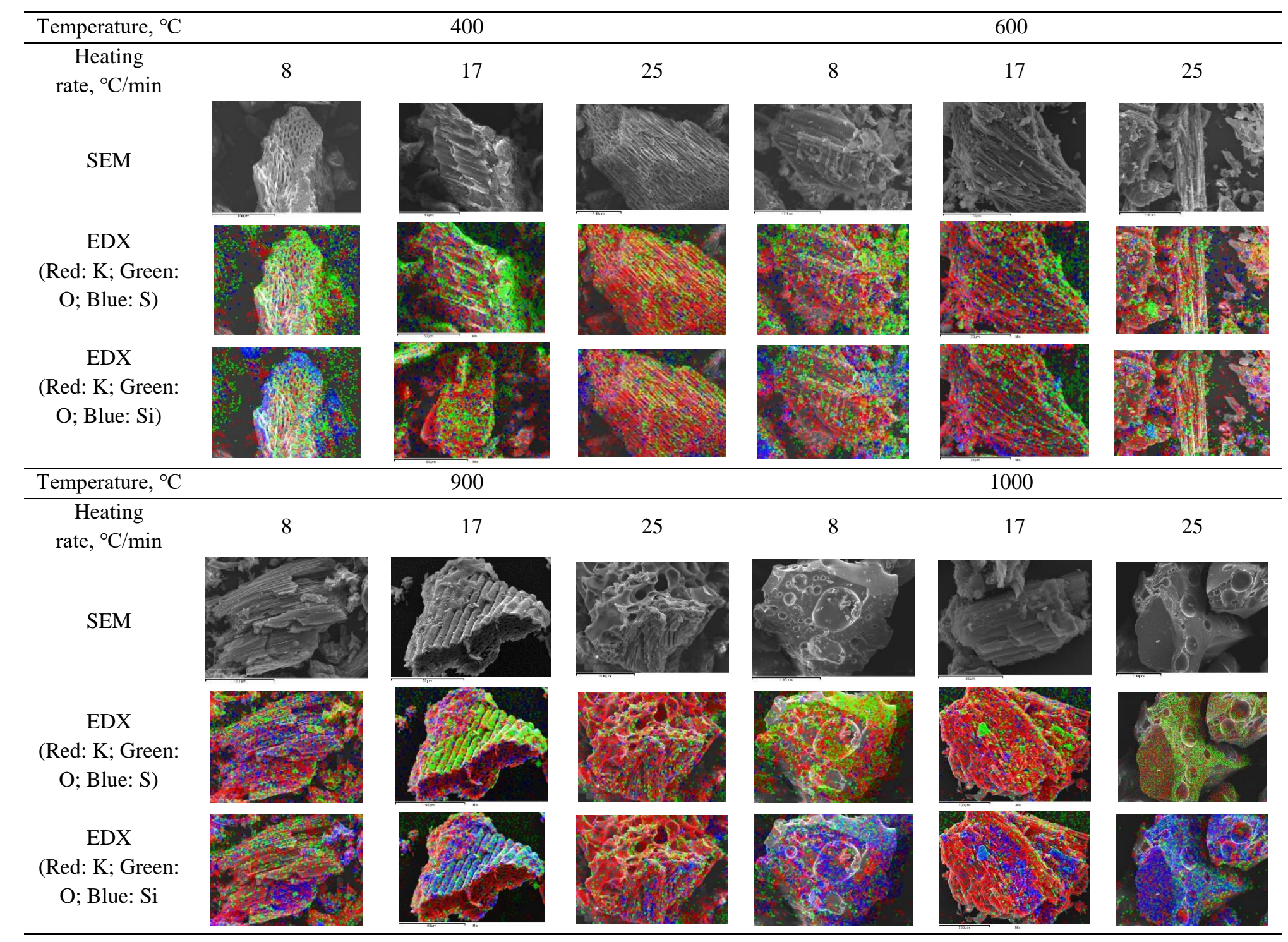

\section{Conclusions}

The influences of final temperature and heating rate on the release and transition performance of $\mathrm{K}$ during biomass combustion have been studied. It is concluded that less $\mathrm{K}$ amount is retained in the solid residues at a higher final temperature. A three-stage mechanism is defined as a function of the final temperature to describe the $\mathrm{K}$ release and transition for the studied wheat straw, including: 
- The initial-step release stage (up to $400^{\circ} \mathrm{C}$ ): the release of loosely bonded $\mathrm{K}$ and partial organic K, which causes about $25 \%$ loss of the initial K content;

- The K-holding stage $\left(400-700^{\circ} \mathrm{C}\right)$ : the transition of existing $\mathrm{K}$ forms from thermally unstable organic-K and char-K to thermally stable inorganic compounds like $\mathrm{KOH}$ and $\mathrm{K}_{2} \mathrm{CO}_{3}$, during which no apparent $\mathrm{K}$ release was detected;

- The second-step release stage (above $700^{\circ} \mathrm{C}$ ): the further release of inorganic $\mathrm{K}$ compounds, during which nearly $30 \%$ extra of the initial $\mathrm{K}$ was finally lost.

Heating rate of biomass materials also influences the $\mathrm{K}$ transition during the combustion. The higher the heating rate is, the less the $\mathrm{K}$ is retained in the solid residues. Compared to samples prepared with the heating rate of $8^{\circ} \mathrm{C} / \mathrm{min}$, all samples made at $25^{\circ} \mathrm{C} / \mathrm{min}$ release $15-20 \%$ more $\mathrm{K}$ in the initial-release stage, around $15 \%$ more in the K-holding stage, and 10-15\% more in the second-release stage.

Comprehensive morphology investigation with elemental distribution mapping analysis has been conducted using SEM-EDX, providing excellent qualitative evidence to the potential relationship between fuel structural evolution and $\mathrm{K}$ transition mechanism. It can be concluded that the majority part of K exists inside the stem-like tunnel of the biomass particles. During the mass conversion of biomass, the breakdown and collapse of its structure could accelerate the release of $\mathrm{K}$ as more internally located $\mathrm{K}$ got exposed. Integrated our experimental results with the targeted literature review, a detailed temperature-dependent mechanism of K release, transition and retention, during biomass combustion, has been proposed.

\section{Acknowledgement}

The authors thank the Scottish Funding Council-Global Challenge Research Fund (SFC1204114), the Leverhulme Trust Research Grant (RPG-2017-254) and EPSRC Grant (EP/R010986/1) for their financial support. 


\section{References}

1. Zhao, H.-b., et al., Study on the transformation of inherent potassium during the fast-pyrolysis process of rice straw. Energy \& Fuels, 2015. 29(10): p. 6404-6411.

2. Zhang, X., Essential scientific mapping of the value chain of thermochemically converted second-generation bio-fuels. Green Chemistry, 2016. 18(19): p. 5086-5117.

3. Hosseini, S.E. and M.A. Wahid, Utilization of palm solid residue as a source of renewable and sustainable energy in Malaysia. Renewable and Sustainable Energy Reviews, 2014. 40: p. 621632.

4. Brunerová, A., M. Brožek, and M. Müller, Utilization of waste biomass from post-harvest lines in the form of briquettes for energy production. Agronomy Research, 2017. 15(2): p. 344-358.

5. Nussbaumer, T., Combustion and co-combustion of biomass: fundamentals, technologies, and primary measures for emission reduction. Energy \& Fuels, 2003. 17(6): p. 1510-1521.

6. Cao, W., et al., Prediction of potassium compounds released from biomass during combustion. Applied Energy, 2019. 250: p. 1696-1705.

7. Saidur, R., et al., A review on biomass as a fuel for boilers. Renewable and Sustainable Energy Reviews, 2011. 15(5): p. 2262-2289.

8. Yang, T., et al., The behavior of alkali metals during the co-combustion of straw and coal. Energy Sources, Part A: Recovery, Utilization, and Environmental Effects, 2014. 36(1): p. 1522.

9. Mason, P.E., et al., Observations on the release of gas-phase potassium during the combustion of single particles of biomass. Fuel, 2016. 182: p. 110-117.

10. Johansen, J.M., et al., Release of $\mathrm{K}, \mathrm{Cl}$, and $\mathrm{S}$ during pyrolysis and combustion of high-chlorine biomass. Energy \& Fuels, 2011. 25(11): p. 4961-4971.

11. Knudsen, J.N., P.A. Jensen, and K. Dam-Johansen, Transformation and release to the gas phase of Cl, K, and S during combustion of annual biomass. Energy \& Fuels, 2004. 18(5): p. 13851399.

12. Van Lith, S.C., et al., Release to the gas phase of inorganic elements during wood combustion. Part 1: development and evaluation of quantification methods. Energy \& Fuels, 2006. 20(3): p. 964-978.

13. Dayton, D.C., R.J. French, and T.A. Milne, Direct observation of alkali vapor release during biomass combustion and gasification. 1. Application of molecular beam/mass spectrometry to switchgrass combustion. Energy \& Fuels, 1995. 9(5): p. 855-865.

14. Fu, P., et al., Study on the gas evolution and char structural change during pyrolysis of cotton stalk. Journal of Analytical and Applied Pyrolysis, 2012. 97: p. 130-136.

15. Meng, X., et al., Release of Alkalis and Chlorine from Combustion of Waste Pinewood in a Fixed Bed. Energy \& Fuels, 2019. 33(2): p. 1256-1266.

16. Fagerström, J., et al., Alkali transformation during single pellet combustion of soft wood and wheat straw. Fuel Processing Technology, 2016. 143: p. 204-212.

17. Johansen, J.M., et al., Release of $\mathrm{K}, \mathrm{Cl}$, and $\mathrm{S}$ during combustion and co-combustion with wood of high-chlorine biomass in bench and pilot scale fuel beds. Proceedings of the Combustion Institute, 2013. 34(2): p. 2363-2372.

18. Liu, Y., et al., Characteristics of alkali species release from a burning coal/biomass blend. Applied Energy, 2018. 215: p. 523-531.

19. Sommersacher, P., et al., Simultaneous Online Determination of $\mathrm{S}, \mathrm{Cl}, \mathrm{K}, \mathrm{Na}, \mathrm{Zn}$, and $\mathrm{Pb}$ Release from a Single Particle during Biomass Combustion. Part 1: Experimental SetupImplementation and Evaluation. Energy \& Fuels, 2015. 29(10): p. 6734-6746.

20. Sommersacher, P., et al., Simultaneous online determination of $\mathrm{S}, \mathrm{Cl}, \mathrm{K}, \mathrm{Na}, \mathrm{Zn}$, and $\mathrm{Pb}$ release from a single particle during biomass combustion. Part 2: results from test runs with spruce and straw pellets. Energy \& Fuels, 2016. 30(4): p. 3428-3440.

21. Fatehi, H., et al., LIBS measurements and numerical studies of potassium release during biomass gasification. Proceedings of the Combustion Institute, 2015. 35(2): p. 2389-2396. 
22. Striūgas, N., M. Sadeckas, and R. Paulauskas, Investigation of $\mathrm{K}^{*}, \mathrm{Na}^{*}$ and $\mathrm{Ca}^{*}$ flame emission during single biomass particle combustion. Combustion Science and Technology, 2019. 191(1): p. $151-162$.

23. Cao, W., et al., Experimental study on the influences of operating parameters on the retention of potassium during the biomass combustion. Energy Procedia, 2019. 158: p. 1033-1038.

24. Cao, W., J. Li, and L. Lue, Study on the ignition behavior and kinetics of combustion of biomass. Energy Procedia, 2017. 142: p. 136-141.

25. Koppejan, J. and S. Van Loo, The handbook of biomass combustion and co-firing. 2012: Routledge.

26. Tchoffor, P.A., et al., Influence of fuel ash characteristics on the release of potassium, chlorine, and sulfur from biomass fuels under steam-fluidized bed gasification conditions. Energy \& Fuels, 2016. 30(12): p. 10435-10442.

27. Design, R., Chemkin-Pro 15131. 2013, Reaction Design San Diego, CA.

28. Blomberg, T., A thermodynamic study of the gaseous potassium chemistry in the convection sections of biomass fired boilers. Materials and Corrosion, 2011. 62(7): p. 635-641.

29. Vassilev, S.V., D. Baxter, and C.G. Vassileva, An overview of the behaviour of biomass during combustion: Part II. Ash fusion and ash formation mechanisms of biomass types. Fuel, 2014. 117: p. 152-183.

30. Clery, D.S., et al., The effects of an additive on the release of potassium in biomass combustion. Fuel, 2018. 214: p. 647-655.

31. Saddawi, A., J. Jones, and A. Williams, Influence of alkali metals on the kinetics of the thermal decomposition of biomass. Fuel Processing Technology, 2012. 104: p. 189-197.

32. $\mathrm{Yu}, \mathrm{C}$. and $\mathrm{W}$. Zhang, Modeling potassium release in biomass pyrolysis. Progress in Thermochemical Biomass Conversion, 2001: p. 1107-1115.

33. Jensen, P.A., et al., Experimental investigation of the transformation and release to gas phase of potassium and chlorine during straw pyrolysis. Energy \& Fuels, 2000. 14(6): p. 1280-1285.

34. Akbar, S., U. Schnell, and G. Scheffknecht, Modelling potassium release and the effect of potassium chloride on deposition mechanisms for coal and biomass-fired boilers. Combustion Theory and Modelling, 2010. 14(3): p. 315-329.

35. Reid, J., et al., A review of biomass burning emissions part II: intensive physical properties of biomass burning particles. Atmospheric Chemistry and Physics, 2005. 5(3): p. 799-825.

36. Glassman, I., R.A. Yetter, and N.G. Glumac, Chapter 9 - Combustion of nonvolatile fuels, in Combustion (Fifth Edition), I. Glassman, R.A. Yetter, and N.G. Glumac, Editors. 2015, Academic Press: Boston. p. 477-536.

37. Feng, B. and S.K. Bhatia, Percolative Fragmentation of Char Particles during Gasification. Energy and Fuels, 2000. 14(2): p. 297-307.

38. Idris, S.S., N.A. Rahman, and K. Ismail, Combustion characteristics of Malaysian oil palm biomass, sub-bituminous coal and their respective blends via thermogravimetric analysis (TGA). Bioresource Technology, 2012. 123: p. 581-591.

39. Sander, B., et al. Emissions, corrosion and alkali chemistry in straw-fired combined heat and power plants. in 1st World Conference and Exhibition on Biomass for Energy and Industry. 2000.

40. Baxter, L.L., et al., The behavior of inorganic material in biomass-fired power boilers: field and laboratory experiences. Fuel Processing Technology, 1998. 54(1-3): p. 47-78.

41. Zhang, Z.-H., et al., Influence of the atmosphere on the transformation of alkali and alkaline earth metallic species during rice straw thermal conversion. Energy \& Fuels, 2012. 26(3): p. 1892-1899.

42. Bostrom, D., et al., Ash transformation chemistry during combustion of biomass. Energy \& Fuels, 2011. 26(1): p. 85-93.

43. Li, C.-Z. and P.F. Nelson, Fate of aromatic ring systems during thermal cracking of tars in a fluidized-bed reactor. Energy \& Fuels, 1996. 10(5): p. 1083-1090.

44. Sathe, C., Y. Pang, and C.-Z. Li, Effects of heating rate and ion-exchangeable cations on the pyrolysis yields from a Victorian brown coal. Energy \& fuels, 1999. 13(3): p. 748-755.

45. Kershaw, J.R., et al., Fluorescence spectroscopic analysis of tars from the pyrolysis of a Victorian brown coal in a wire-mesh reactor. Energy \& Fuels, 2000. 14(2): p. 476-482. 
46. Fushimi, C., et al., Effect of heating rate on steam gasification of biomass. 1. Reactivity of char. Industrial \& Engineering Chemistry Research, 2003. 42(17): p. 3922-3928.

47. Mehrabian, R., R. Scharler, and I. Obernberger, Effects of pyrolysis conditions on the heating rate in biomass particles and applicability of TGA kinetic parameters in particle thermal conversion modelling. Fuel, 2012. 93: p. 567-575.

48. Milosavljevic, I. and E.M. Suuberg, Cellulose thermal decomposition kinetics: global mass loss kinetics. Industrial \& Engineering Chemistry Research, 1995. 34(4): p. 1081-1091.

49. Grønli, M., M.J. Antal, and G. Varhegyi, A round-robin study of cellulose pyrolysis kinetics by thermogravimetry. Industrial \& Engineering Chemistry Research, 1999. 38(6): p. 2238-2244.

50. Biagini, E., A. Fantei, and L. Tognotti, Effect of the heating rate on the devolatilization of biomass residues. Thermochimica Acta, 2008. 472(1-2): p. 55-63.

51. Garcia-Maraver, A., et al., Determination and comparison of combustion kinetics parameters of agricultural biomass from olive trees. Renewable Energy, 2015. 83: p. 897-904.

52. Mermoud, F., et al., Influence of the pyrolysis heating rate on the steam gasification rate of large wood char particles. Fuel, 2006. 85(10-11): p. 1473-1482.

53. German, R., Sintering: from empirical observations to scientific principles. 2014: ButterworthHeinemann.

54. Luo, Y.-R., Comprehensive handbook of chemical bond energies. 2007: CRC press.

55. Zygourakis, K., Effects of pyrolysis conditions on the macropore structure of coal chars. Prepr. Pap., Am. Chem. Soc., Div. Fuel Chem.;(United States), 1988. 33(CONF-8809228-).

56. Basu, P., Biomass gasification and pyrolysis: practical design and theory. 2010: Academic press.

57. Kumar, M. and R.C. Gupta, Influence of carbonization conditions on the gasification of acacia and eucalyptus wood chars by carbon dioxide. Fuel, 1994. 73(12): p. 1922-1925. 